\section{Differential staining of neuronal and glial nuclei}

SERGE DUCKETT From the Department of Neurology and Pathology of Jefferson Medical College of the Thomas Jefferson University, Philadelphia, Pa.

The histological differentiation of neuronal from glial nuclei may be useful in the identification of tumours and in the study of developing nervous tissues. The following method does this by staining the glial nucleus red and the neuronal nucleus green. It also stains other structures in the neural parenchyma. Formol-fixed tissues taken down to water and embedded in paraffin are used.

1 The sections $(10 \mu)$ are placed for 10 minutes in $1 \%$ brilliant crystal scarlet (Ponceau $\mathrm{R}$ or Xyledine) solution made up with $1 \%$ acetic acid diluted in distilled water.

2 Washed in distilled water

3 Five minutes in $0.5 \%$ phosphotungstic acid

4 Washed briefly in distilled water

5 Stained 30 seconds to one minute in $1 \%$ methyl green (made with distilled water)

6 Washed in distilled water

7 Dehydrate, clear, and mount in DPX

The glial nucleus stains red, neuronal nucleus green, the nucleolus red, myelin red, axons green, red blood cells red, and connective tissue red.

Received for publication 27 April 1972.

An immunological method for the detection and estimation of fetal haemoglobin - continued

Chernoff, A. I. (1953). Immunological studies of haemoglobins. II. Quantitative precipitin test using anti-fetal haemoglobin. Blood, 8, 413-421.

Kohn, J. (1970). Method for the detection and identification of alpha-fetoprotein in serum. J. clin. Path., 23, 733-735.

Mancini, G., Vaerman, J. P., Carbonara, A. O., and Heremans, J. F. (1963). A single-radial-immunodiffusion method for the immunological quantitation of proteins. Prot. biol. Fluids, 11, 370 .
Improved sensitivity of the electrophoresis method by tannic acid for detection of Australia antigen

R. HOPKINS AND P. C. DAS

From the Regional Transfusion Service, Royal Infirmary, Edinburgh

For detection of Australia antigen (Au-Ag) bie counter-immunoelectroosmophoresis (CIEOP) stainto ing the agarose gel plates with certain dyes has beeg claimed to improve the sensitivity (Combridge an Shaw, 1971). In our experience, however, a simplef and less time-consuming procedure is that of layering the gel plates with $1 \%$ freshly made tannic for 10 minutes (Alpert, Munroe, and Schur, 1970) after thळ routine CIEOP procedure (Das, Hopkins, Cash, an Cumming, 1971). This has resulted in a significantly increased sensitivity by improving visualization $O D$ precipitin lines.

Serial dilutions of $\mathrm{Au}-\mathrm{Ag}$ containing serum क्षिद्य anti-Au (human origin) were set up in the thest system using a 'chessboard' design. After the elector phoresis 'run' the gel plates were observed at an angls under direct light over a dark background. Tho results were scored as + for sharp precipitin lineơ \pm for weak precipitation, and - for no reaction Table I shows that the titre of $\mathrm{Au}-\mathrm{Ag}$ against th $\overrightarrow{\mathrm{g}}$ neat antiserum was $1 / 4$, and no significant improve 3 ment was noticed when the same plate was reviewe after overnight incubation. Tannic acid was now. added and the plate read after 10 minutes: the titre was now $1 / 16$. This improvement reflects an in creased sensitivity of the system as a whole; thus before tannic acid treatment, the total number Received for publication 11 May 1972.

\begin{tabular}{|c|c|c|c|c|c|c|c|c|c|c|c|c|c|}
\hline \multirow[t]{3}{*}{$A u-A g$ Dilutions } & \multicolumn{4}{|c|}{$\begin{array}{l}\text { Counter Immunoelectrophoresis } \\
\text { Routine }\end{array}$} & \multicolumn{4}{|c|}{ Overnight Incubation } & \multicolumn{4}{|c|}{ After Tannic Acid } & $\frac{1}{2}$ \\
\hline & \multicolumn{8}{|c|}{ Anti-Au Dilutions } & & & & & $N$ \\
\hline & Neat & & $1 / 4$ & & Neat & & $1 / 4$ & & \multicolumn{2}{|l|}{ Neat } & \multicolumn{3}{|l|}{$1 / 4$} \\
\hline \multirow[t]{2}{*}{ Neat } & $\cdots$ & - & $\because$ & - & + & & $\cdots$ & . & + & $\because$ & + & + & $N$ \\
\hline & . & $\because$ & $\cdots$ & $\cdots$ & - & - & + & $T$ & + & - & + & + & $\omega$ \\
\hline $1 / 4$ & - & $\ddot{-}$ & - & $\ddot{\cdots}$ & - & - & $\therefore$ & + & $\therefore$ & $\therefore$ & + & + & 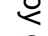 \\
\hline \multirow[t]{3}{*}{$1 / 16$} & - & - & - & - & - & - & - & - & $\div$ & $=$ & $i$ & + & $\stackrel{0}{0}$ \\
\hline & - & - & - & - & - & - & - & - & - & - & - & \pm & $\bar{D}$ \\
\hline & Total & itive & 14 & & & & 14 & & & & 21 & & \\
\hline
\end{tabular}

Table I Results on serial dilutions of Au-Ag and Anti-Au tested in a 'chessboard' fashion before and after tannic acid' treatment 